Published in final edited form as:

N Engl J Med. 2012 August 16; 367(7): 595-605. doi:10.1056/NEJMoa1201637.

\title{
Quality-of-life effects of prostate-specific antigen screening
}

\author{
EAM Heijnsdijk, Ph.D. ${ }^{1}$, EM Wever, M.Sc. ${ }^{1}$, A Auvinen, M.D. ${ }^{2}$, J Hugosson, M.D. ${ }^{3}$, S Ciatto, \\ M.D. ${ }^{4}$, V Nelen, M.D. ${ }^{5}$, M Kwiatkowski, M.D. ${ }^{6}$, A Villers, M.D. ${ }^{7}$, A Páez, M.D. ${ }^{8}$, SM Moss, Ph.D. \\ ${ }^{9}$, M Zappa, M.D. ${ }^{10}$, TLJ Tammela, M.D. ${ }^{11}$, T Mäkinen, M.D. ${ }^{12}$, S Carlsson, M.D. ${ }^{3,13}$, IJ \\ Korfage, Ph.D. ${ }^{1}$, ML Essink-Bot, Ph.D. ${ }^{14}$, SJ Otto, Ph.D. ${ }^{1}$, G Draisma, Ph.D. ${ }^{1}$, CH Bangma, \\ M.D. ${ }^{15}$, MJ Roobol, Ph.D. ${ }^{15}$, FH Schröder, M.D. ${ }^{15}$, and HJ de Koning, M.D. ${ }^{1}$
}

${ }^{1}$ Department of Public Health, Erasmus Medical Center, Rotterdam, the Netherlands ${ }^{2}$ Tampere School of Health Sciences, University of Tampere, Tampere, Finland Part of the work was carried out during the tenure of a Senior Visiting Scientist at the International Agency for Research on Cancer, Lyon, France ${ }^{3}$ Department of Urology, Sahlgrenska University Hospital, Gothenburg, Sweden ${ }^{4}$ Department of Diagnostic Medical Imaging, Institute for Cancer Prevention, Florence, Italy ${ }^{5}$ Provinciaal Instituut voor Hygiëne, Antwerp, Belgium ${ }^{6}$ Department of Urology, Kantonsspital Aarau, Aarau, Switzerland ${ }^{7}$ Department of Urology, Centre Hospitalier Regional Universitaire, Lille, France ${ }^{8}$ Department of Urology, Hospital de Fuenlabrada, Madrid, Spain ${ }^{9}$ Centre for Cancer Prevention, Queen Mary University of London, United Kingdom ${ }^{10}$ Unit of Epidemiology, Institute for Cancer Prevention, Florence, Italy ${ }^{11}$ Department of Urology, Tampere University Hospital and University of Tampere, Tampere, Finland ${ }^{12}$ Department of Surgery, Seinäjoki Central Hospital, Seinäjoki, Finland ${ }^{13}$ Memorial Sloan-Kettering Cancer Center, Department of Surgery (Urology), New York, US ${ }^{14}$ Department of Public Health, Academic Medical Center, University of Amsterdam, Amsterdam, the Netherlands ${ }^{15}$ Department of Urology, Erasmus Medical Center, Rotterdam, the Netherlands

\section{Abstract}

Background-The European Randomized Study of Screening for Prostate Cancer (ERSPC) reported a $29 \%$ prostate cancer mortality reduction among screened men after 11 years. However, it is uncertain to what extent harms from overdiagnosis and treatment on quality of life counterbalance this benefit.

Methods-Based on ERSPC follow-up data, we used micro-simulation modeling (MISCAN) to predict the number of prostate cancers, treatments, deaths and quality-adjusted life-years (QALYs) gained following the introduction of screening. Various screening strategies, efficacies, and quality of life assumptions were modeled.

Results-Per 1,000 men of all ages followed for their entire lifespan we predicted for annual screening from age 55-69 years: 9 fewer deaths due to prostate cancer (28\% reduction), 14 fewer men receiving palliative therapy (35\% reduction), and 73 life-years gained (average 8.4 years per prostate cancer death avoided). QALYs gained were 56 (range: $-21,97$ ), a reduction of $23 \%$ from unadjusted life-years gained. The number needed to screen (NNS) was 98 and number needed to detect (NND) 5. Also inviting men aged 70-74 resulted in more life-years (82) but similar QALYs (56). 
Conclusions-Although NNS and NND are more favorable than previously calculated, the benefit of PSA screening is diminished by loss of QALYs, that is dependent primarily on postdiagnosis long-term effects. Longer follow-up data from both the ERSPC and quality of life are essential before making universal recommendations regarding screening.

\section{Introduction}

The initial results of the European Randomized Study of Screening for Prostate Cancer (ERSPC) showed a significant prostate cancer mortality reduction in the screening group of $20 \%$ after a median follow-up of nine years, and of $27 \%$ in screened men when adjusted for selection bias. ${ }^{1}$ The results have recently been updated, resulting after 11 years in a prostate cancer mortality reduction of $29 \%$ in men screened when adjusted for selection bias. ${ }^{2}$ The Gothenburg trial, one center of the ERSPC, reported a prostate cancer mortality reduction of $44 \%$ after a median follow-up of 14 years and a $56 \%$ reduction for men screened at least once. $^{3}$ The U.S. Prostate, Lung, Colorectal and Ovarian (PLCO) Cancer Screening Trial found no mortality reduction in the screening group, however the rate of contamination was high and biopsy compliance low. ${ }^{4}$

Prostate cancer mortality reduction, life-years gained and a reduction of advanced disease are obvious benefits of screening. However, PSA screening is associated with considerable unfavorable effects. In the ERSPC screening group, the cumulative incidence of prostate cancer was $7.4 \%$, versus $5.1 \%$ in the control group ${ }^{2}$. A proportion of the screen-detected tumors $(10-56 \%)$ would never have led to clinical symptoms ${ }^{5-8}$ but these overdiagnosed cancers are frequently treated nonetheless with associated risks of adverse effects. ${ }^{9}$ Furthermore, because of a long lead-time, estimated at 5-12 years ${ }^{6,10}$, men have to live longer with those effects.

Reports on the harms and benefits of PSA screening are highly inconsistent due to the lack of results from randomized screening trials. ${ }^{11,12}$ However, as more mature data from the ERSPC are available, for the first time realistic predictions of the effects of screening can be made. Therefore, this study quantifies the effects of screening strategies on prostate cancer mortality and quality of life, using a model based on data from the ERSPC. In addition, we have determined the harms and benefits for a range of treatment, mortality reductions and screening scenarios.

\section{Methods ERSPC data}

The ERSPC was initiated in the early 1990s to evaluate the effect of PSA screening on prostate cancer mortality ${ }^{13}$. In seven countries, 162,243 men were randomized. Most centers used a PSA cutoff value of $3.0 \mathrm{ng} / \mathrm{mL}$ as an indication for biopsy, others used $4.0 \mathrm{ng} / \mathrm{mL}$, with additional tests for values between 2.5 and 4.0. The screening interval was 4 years, with the exception of Sweden (2 years). Treatment was performed according to local policies and guidelines, independent of trial $\mathrm{arm}^{14}$. In line with the protocol, the effect of screening in the core age group (55-69 years) was evaluated. Follow-up data on mortality until 31 December 2008 are currently available ${ }^{2}$. 
We used Microsimulation Screening Analysis (MISCAN) to extrapolate the results to alternative screening strategies and an extended follow-up.

\section{Screening strategies}

A population of men aged 0-100 years was simulated with an age distribution according to the European Standard Population. ${ }^{15}$ The following screening strategies were simulated: annual screening in the age groups 55-69 years and 55-74 years, screening at 4-year intervals between 55-69, and single screens performed either at age 55, 60 or 65 years. An $80 \%$ participation proportion was assumed.

\section{Quality of life}

Quality-adjusted life-years (QALYs) were predicted using utility estimates for various health states. The utility estimates were obtained from the CEA Registry ${ }^{16}$ and literature (Table 1) and ranged from 0 (death or worst imaginable health) to 1 (full health). In addition, data from ERSPC on treatment-related complications as urinary incontinence, bowel dysfunction and erectile dysfunction were analyzed. Favorable and unfavorable values were assigned according to the minimum and maximum values in the cited references. A utility estimate of 0.99 was used for the screening phase, because prostate cancer screening has little effect on short-term health status and anxiety. ${ }^{17}$ The health states of men receiving treatment were divided into 2 months of treatment, an intermediate period (10 months of recovery from treatment), and a post-recovery period (1-10 years after treatment). Utility estimates for this post-recovery period were obtained by combining the percentage of men with side-effects from the treatment ${ }^{18}$ with the utility estimates for those side-effects. ${ }^{19}$ This led to a utility estimate of 0.95 for all men during the period 1-10 years after diagnosis and after receiving radical prostatectomy or radiation therapy. The loss in quality of life was calculated by multiplying the loss in utility by the duration of the health state and the number of men in that state as predicted by MISCAN.

\section{The MISCAN model}

MISCAN was used to model prostate cancer screening. 5,6 This model simulates individual life histories stochastically. The natural history of prostate cancer starts with a transition from 'no prostate cancer' to preclinical screen-detectable prostate cancer in a subset of the population. From each preclinical stage, the tumor may become screen detected, clinically diagnosed, or progress into a more advanced preclinical stage.

In the model, prostate cancers were characterized according to their clinical T-stage (T1 impalpable, T2 palpable, confined to the prostate and T3+ palpable, with extension beyond the prostatic capsule), differentiation grade (Gleason score $\leq 7,7$, or $\geq 7$ ) and metastatic stage (locoregional or distant). The parameters for the natural history of the disease and for stagespecific test sensitivities (0.82-0.98 depending on clinical T-stage and Gleason score) were first estimated using incidence in the Dutch population during 1992-2002 (a period with limited opportunistic screening $)^{20}$ and using age and stage distributions from the Rotterdam and Gothenburg sections of the ERSPC, being the largest centers, that varied in randomization, recruitment and screening interval. In a second phase, this model was 
validated using screen data from all centers. The model and calibration methods and results are described in the Appendix.

Treatment assignment for locoregional cases in MISCAN was based on the age-, stage- and Gleason score-specific primary treatments (radiation therapy, radical prostatectomy and active surveillance) assigned in both arms of the ERSPC. All men with metastases and all men dying of prostate cancer were assumed to receive palliative treatment. The proportion of men receiving treatment within 7 years after having started using active surveillance was based on recent data. ${ }^{21}$

Survival of unscreened men diagnosed with locoregional prostate cancer was modeled using Gleason score-specific survival curves. ${ }^{22}$ These data are from a large unscreened cohort, followed for a median period of 24 years, and the data are available by age, stage and grade. For distant disease, survival curves were based on SEER data. The effects of treatment were modeled by assuming a relative risk of dying from prostate cancer of 0.65 for radical prostatectomy ${ }^{23}$ compared with watchful waiting. This effect was also assumed for radiation therapy.

A proportion of the screen-detected men with a locoregional cancer will be cured. In the base model, this stage-dependent cure proportion was estimated by calibrating to a prostate cancer mortality reduction of $29 \%$ after 11 years follow-up of screening at 4-year intervals for men who attended at least one screen, corresponding to the ERSPC ${ }^{2}$. This estimated cure proportion was used as an input to the model. Cure proportions were also estimated for hypothetical prostate cancer mortality reductions of $31 \%$ (estimated reduction adjusted for noncompliance and contamination), ${ }^{24} 35 \%$ and $39 \%$ (the intended reduction to reach of the trial in the Gothenburg center) after nine years follow-up, and of 56\% after 14 years followup (the Gothenburg trial) ${ }^{3}$. In the model, all screened men with prostate cancer who are cured will die from other causes at the time they would have died had they not had prostate cancer. The screened men who are not cured from prostate cancer will die at the same moment as they would have if they had not been screened. The effects of screening were calculated from 2010 until 2110, when all men will have died.

This study was designed by Heijnsdijk and de Koning. ERSPC data were gathered by each individual center and analyzed by the epidemiology committee led by Moss. Modeling was performed by Heijnsdijk, Wever, Draisma and de Koning. Quality of life data were provided by Carlsson and Korfage. The first draft was written by Heijnsdijk, with all co-authors participating in several revisions and the decision to publish the manuscript. There were no agreements concerning confidentiality of the data between the sponsors and the authors or the institutions.

\section{Results}

\section{Quality of life following treatment}

Two specific studies on quality of life after prostate cancer treatment have been performed for men participating in Rotterdam and Sweden 9 , 25 . Pre-operatively $1-2 \%$ of the men were incontinent and $31-40 \%$ were impotent. After $18-52$ months $6-16 \%$ of the radical 
prostatectomy patients and 3\% of the radiation therapy patients were incontinent (Table 2). Six to 52 months after a radical prostatectomy, $83-88 \%$ of pre-operatively potent men became impotent, compared with $42-66 \%$ of the men receiving radiation therapy. In general, screen detected men had fewer complaints postoperatively than clinically detected men (Appendix Table S4). This difference could be a result of aging, due to later diagnosis in the unscreened group. These ERSPC data are consistent with data from a large international cohort (Appendix Figure S7).

\section{Predicted effects of annual screening at 55-69 years (base model)}

The number of men experiencing each of the various health states in both the absence and presence of annual screening was modeled over the lifetime of 1,000 men (Table 3). The number of life-years and QALYs gained or lost as a result of the differences between the numbers of men experiencing each health state were also calculated. The model predicted that a total of 73 life-years would be gained through the introduction of annual screening. The number of prostate cancer diagnoses was predicted to increase by screening from 112 cases to 157 cases ( $40 \%$ increase). The number of prostate cancer deaths was predicted to decrease from 31 to 22 (28\% decrease), and the number of men receiving palliative care was predicted to decrease from 40 to 26 (35\% reduction). The total number of life-years gained per prostate cancer death avoided was 8.4 years (73/9). Among screened men, there was a $37 \%$ prostate cancer mortality reduction over the entire lifetime (Table 4 ).

The predicted adverse effects of screening were 247 additional negative biopsies and 41 additional men receiving radical prostatectomy or radiation therapy. The model predicted a gain of 56 QALYs (range: $-21,97$ ), which means that $(73-56) / 73=23 \%$ of the unadjusted life-years gained would be counterbalanced by loss in quality of life. This loss was primarily attributable to the short and long-term effects of primary treatment and a longer postrecovery period with side effects.

The number of QALYs predicted to be gained in the base model was also calculated in sensitivity analyses considering various assumptions for overdiagnosis, screening attendance, and utility estimates (Figure 1). A hypothetical situation without overdiagnosis was predicted to yield a gain of 79 QALYs. Screening attendance ranging from 50-100\% was predicted to produce a gain of 30-60 QALYs (23\% adjusted of 39 and 78 life-years gained, respectively). The most favorable utility estimates resulted in 97 QALYs gained, and the least favorable in 21 QALYs lost. The utility estimate for the post-recovery period had a considerable impact. If no loss in utility in this period was assumed, screening resulted in 72 QALYs gained, whereas a utility estimate of 0.93 instead of 0.95 for the remaining life-time resulted in 6 QALYs gained. A utility estimate of 0.95 during the first 5, 7, or 15 years after diagnosis in combination with no loss in utility after that period resulted in a gain of 66, 62 and 47 QALYs, respectively (results not shown in graph). Other utility estimates besides those for the post-recovery period and for palliative therapy had minor impact on the results.

In the base model, 104 cancers were screen detected, and $45(43 \%)$ of these were overdiagnosed (Table 4). Overdiagnosed cancers are screen-detected cancers that would not have become clinically diagnosed during a person's lifetime in the absence of screening. The prostate cancer mortality reduction in a steady state (20 years after the start of screening) for 
men who attended at least one screening was estimated at $37 \%$. The predicted number of men needed to screen (NNS) to prevent one prostate cancer death was $98(845 / 9)$, and the number of men needed to detect (NND) to prevent one prostate cancer death was $5(45 / 9)$.

The predicted effects of various cure rates, based on various mortality reductions are described in the Appendix.

\section{Predicted effects of screen strategies}

Extending the screening age to 74 years resulted in an overall gain of 82 life-years and an increase in the number of prostate cancer deaths prevented from 9 to 11 (Table 4). However, the model predicts that only 56 QALYs (range: $-47,111$ ) would be gained, representing a $32 \%$ reduction in unadjusted life-years. This reduction in quality of life is mainly due to the large number of overdiagnosed cases (48\% of the screen detected cancers) and the 372 additional negative biopsies that would occur. On the other hand, the NNS was more favorable (84) compared with screening up to age 69.

Screening at 4-year intervals at age 55-69 years led to a gain of 52 life-years and 41 QALYs (range: $-10,69$ ). There was a steady-state prostate cancer mortality reduction of $21 \%$ and the NNS was 129.

A single screen at age 55,60, or 65 resulted in the detection of fewer cancers but also in less overdiagnosis. The steady-state prostate cancer mortality reduction was $27-31 \%$ and the life-years gained ranged from $12-25$. The NNS for a single screen at 55, 60, or 65 years of age were 490, 249, and 186, respectively.

\section{Discussion}

Weighing the balance between the benefits and harms of prostate cancer screening is essential for decision-making regarding screening at both individual and policy level. Our model predicts that there would be 9 fewer prostate cancer deaths and 73 life-years gained over the lifetime of 1,000 men using annual screening between the ages of 55-69 years. The harms caused by the introduction of such screening would be the overdiagnosis and overtreatment of 45 cases, and the loss of 1,134 prostate cancer-free life-years (lead time years). Adjusting the number of life-years gained from screening by consideration of quality of life effects showed that 56 QALYs would be gained, which is a $23 \%$ reduction from the predicted number of life-years gained.

We used a one-year screening interval in the base runs to comply with existing practice in the USA, however, the conclusions are comparable with a 4-year interval.

The NNS (98) and NND (5) predicted in the base model are more favorable than reported in the earlier results of the ERSPC (1068 and 48, respectively). ${ }^{1}$ The Gothenburg trial reported a NNS of 293 and a NND of 12 at 14 years follow-up. ${ }^{3}$ Our model predicts long-term effects after a much longer period. After eleven years, the cumulative incidence of prostate cancer in the ERSPC screening group far exceeded that in the control group (9.7 versus 6.0 per 1000 person-years); however, the control group will partly catch-up because of the leadtime, and therefore the absolute difference between the groups will decrease. In addition, the 
absolute difference in prostate cancer deaths is likely to increase over time, reducing the NNS and the NND.

A substantial part of the predicted difference between life-years and QALYs gained is caused by overdiagnosed cancers. The proportion of overdiagnosed cases ( $42 \%$ of the screen-detected cancers) predicted in the base model is comparable to previous studies. ${ }^{6}$ Strategies to reduce overdiagnosis would seem to be necessary before screening can be generally advocated. Distinguishing indolent cancers from aggressive cancers, will be crucial. ${ }^{26,27}$ More active surveillance, and deferring treatment until early signs of disease progression may also increase the QALYs gained. ${ }^{28,} 29$

The optimal screening strategy can also depend on co-morbidity status. In our model we used general life tables for other cause mortality and therefore the distribution of comorbidity was that of a general population. We can roughly estimate the effect of comorbidity by adjusting the life tables. For example for men of 65 having the life expectancy of men of 62 (low co-morbidity), annual screening from age 55-69 resulted in 93 life years gained and 80 QALYs gained (an adjustment of 14\%) and annual screening until age 75 resulted in 108 life years gained and 86 QALYs gained (an adjustment of 20\%). Therefore, screening until age 75 in men with low co-morbidity has approximately the same adjustment for quality of life as screening until age 69 in the general population.

The $23 \%$ predicted reduction in life-years gained due to quality of life effects is higher than the $8 \%$ estimated for breast cancer screening. ${ }^{30}$ In addition to cancer deaths avoided, screening for breast cancer allows the use of less radical treatment (e.g. lumpectomy vs. mastectomy) in early detected cancers, whereas screening for prostate cancer leads to a substantial increase in treatments, especially when active surveillance strategy for indolent disease is not embraced. Also, an average of 15 life-years are gained per breast cancer death prevented while (due to older age at diagnosis and shorter life expectancy among men) only 8.4 life-years are gained per prostate cancer death prevented.

The predicted adjustment for quality of life is due to the long-term side-effects from treatment. Both over-diagnosed and non-overdiagnosed men will live many years with adverse effects of treatment. For example, in the post-recovery period, 5 life-years were adjusted for the non-overdiagnosed men and 11 life-years for the overdiagnosed men. How these side-effects influence the long-term quality of life is not well studied. Most side-effects affecting the urinary tract and bowel will improve after some years, but significant symptoms persist in many patients up to 5 years after treatment. ${ }^{18,31,32}$ Although patients can adapt to these effects, ${ }^{33,34}$ partly because they consider themselves cured from a lifethreatening disease (though they could be overdiagnosed), they still report lower physical functioning 5-10 years after treatment than a control group of similar age ${ }^{31,35,36}$. The results from a study of the urinary, bowel and sexual function over time after radical prostatectomy and radiation therapy, measured within the ERSPC have been compared with one of the largest studies outside the ERSPC ${ }^{37}$ (Appendix). General patterns are similar: there is an improvement in function over time until a level slightly lower than baseline is reached (Appendix Figure S7). A published analysis used a decremented post-treatment 
utility for life-time ${ }^{38}$. In our base model we used a utility estimate of 1 for the time period more than ten years after diagnosis, assuming improvement of symptoms.

One limitations of our model is that some of the utility estimates used in the present analysis are based on studies performed in the USA and these may not be representative for Europe. Also, no corrections in utility estimates were made for the detection mode (screen or clinically detected), ${ }^{34}$ for the individual baseline quality of life level ${ }^{39}$, or for improvements in treatments, due to lack of detailed data. It is obvious that decreasing long-term morbidity from treatment is another important goal. However, the perceived effect of treatment on quality of life is subjective. Therefore general recommendations regarding screening do not necessarily apply to the individual.

Another limitation is that we used different datasets to develop the model. We used data from the ERSPC to estimate the parameters that are directly related with screening, or that can only be estimated from such data. For other parameters other sources were more appropriate, because of more extensive populations, more recent data or longer follow-up. We mostly used data from Rotterdam and Gothenburg, because these two large centers have different screening intervals and recruitment and therefore this variation is reflected in the model. Also, the stage distributions match well those of the entire ERSPC and they cover the entire age range. No important differences were found when PSA test sensitivities in Finland, Sweden, and the Netherlands were compared. ${ }^{40}$

We assumed similar effects of radiation treatment as of radical prostatectomy. No clinical trials have directly compared radical prostatectomy with radiation therapy, although some studies have shown a mortality benefit for radical prostatectomy over radiation therapy ${ }^{41,42}$. Assuming a relative risk of dying of 0.7 for radiation treatment would lead to an increase in the number of QALYs of a few percent.

In the Netherlands, men have a lifetime risk of prostate cancer death of 3.5\%. When screening reduces this probability with $30 \%$, this means that 1 per 100 men would die less. This difference is too small to become statistically significant in all-cause mortality in the trial, but indeed would have an impact when screening nationwide.

The next step should be calculating the cost-effectiveness of screening. However, to find the optimal screening strategy, more screening scenarios than the ones presented in this paper should be simulated, including various intervals, starting and stopping ages, and intervals varying by age.

In conclusion, this study quantifies how much of the benefit with the currently reported overall prostate cancer mortality reduction within ERSPC must be adjusted when the harms are taken into consideration. It is essential to await longer follow-up data from the ERSPC, as well as longer-term data on how treatment and active surveillance effects long-term quality of life before more general recommendations could be made regarding mass screening with PSA. 


\section{Supplementary Material}

Refer to Web version on PubMed Central for supplementary material.

\section{Acknowledgments}

This article is dedicated to the memory of Stefano Ciatto, who provided thought-provoking insights into the benefits and harms of cancer screening.

Support:

Supported by grants from Europe Against Cancer and the fifth and sixth framework program of the European Union, by grants from agencies or health authorities in the participating countries, and by unconditional grants from Beckman Coulter. The studies in each center were funded by the following local grants:

The Netherlands:

The Dutch Cancer Society (KWF 94-869, 98-1657, 2002-277, 2006-3518); The Netherlands Organisation for Health Research and Development (ZonMW 002822820, 22000106, 50-50110-98-311).

Belgium:

Europe against Cancer, Flemish Ministry of Welfare, Public Health and Family, Province and City of Antwerp, Public Centre for Social Welfare Antwerp

Sweden:

Abbott Pharmaceuticals, Sweden, Af Jochnick's Foundation, Catarina and Sven Hagstroms Family Foundation, Gunvor and Ivan Svensson's Foundation, Johanniterorden, King Gustav V Jubilée Clinic Cancer Research Foundation, Sahlgrenska University Hospital, Schering Plough, Sweden, Swedish Cancer Society, Wallac Oy, Turkku, Finland.

Finland:

The Academy of Finland (grant \#123054), The Cancer Society of Finland, The Finnish Cancer Institute, The Medical Research Fund of Tampere University Hospital, The Competitive Research Funding of the Pirkanmaa Hospital District, The Sigrid Juselius Foundation, The Pirkanmaa Cancer Society, The Finnish Cultural Foundation, The Helsinki University Central Hospital Research Funds, The Foundation of K. Albin Johansson, The Finska Läkaresällskapet, The Medical Research Fund of Seinäjoki Central Hospital, The Stockman Foundation, The Helsingin Sanomat Centenarian Foundation, The Europe Against Cancer Program, Perkin Elmer-Wallac, Doctoral Programme in Public Heath

Italy:

Italian League for the Fight aganist Cancer - LILT Lega Italiana per la Lotta contro i Tumori

Italian Association for Cancer Research - AIRC Associazione Italiana Ricerca sul Cancro

National Research Council - CNR Consiglio Nazionale delle Ricerche Tuscany Region - Regione Toscana

Spain:

Partially supported by the Spanish Fondo de Investigación Sanitaria (FIS) grants 96/0248, 99/0245, 02/0732 and $06 / 0831$

Switzerland:

The Horten Foundation, Aargau Cancer League, Swiss Cancer League (Grant Nr KFS 787-2-1999 and 01112-02-2001), Health Department of Canton Aargau, Prostate Cancer Research Foundation, Baugarten Foundation and the Messerli Foundation.

International coordination: 
European Union Grants SOC 95 35109, SOC 96201869 05F022, SOC 97 201329, SOC 98 32241, the 6th Framework Program of the EU: PMark:LSHC-CT-2004-503011

Unconditional grants:

Beckman-Coulter-Hybritech Inc.

\section{References}

1. Schröder FH, Hugosson J, Roobol MJ, et al. Screening and prostate-cancer mortality in a randomized European study. N Engl J Med. 2009; 360(13):1320-1328. [PubMed: 19297566]

2. Schröder FH, Hugosson J, Roobol MJ, et al. Prostate cancer mortality at 11-years of follow-up in the European Randomized study of Screening for Prostate Cancer. N Engl J Med. 2011 in press.

3. Hugosson J, Carlsson S, Aus G, et al. Mortality results from the Goteborg randomised populationbased prostate-cancer screening trial. Lancet Oncol. 2010; 11(8):725-732. [PubMed: 20598634]

4. Andriole GL, Crawford ED, Grubb RL 3rd, et al. Mortality results from a randomized prostatecancer screening trial. N Engl J Med. 2009; 360(13):1310-1319. [PubMed: 19297565]

5. Draisma G, Boer R, Otto SJ, et al. Lead times and overdetection due to prostate-specific antigen screening: estimates from the European Randomized Study of Screening for Prostate Cancer. J Natl Cancer Inst. 2003; 95(12):868-878. [PubMed: 12813170]

6. Draisma G, Etzioni R, Tsodikov A, et al. Lead time and overdiagnosis in prostate-specific antigen screening: importance of methods and context. J Natl Cancer Inst. 2009; 101(6):374-383. [PubMed: 19276453]

7. Telesca D, Etzioni R, Gulati R. Estimating lead time and overdiagnosis associated with PSA screening from prostate cancer incidence trends. Biometrics. 2008; 64(1):10-19. [PubMed: 17501937]

8. Zappa M, Ciatto S, Bonardi R, Mazzotta A. Overdiagnosis of prostate carcinoma by screening: an estimate based on the results of the Florence Screening Pilot Study. Ann Oncol. 1998; 9(12):12971300. [PubMed: 9932159]

9. Korfage IJ, Essink-Bot ML, Borsboom GJ, et al. Five-year follow-up of health-related quality of life after primary treatment of localized prostate cancer. Int J Cancer. 2005; 116(2):291-296. [PubMed: 15800919]

10. Hugosson J, Aus G, Becker C, et al. Would prostate cancer detected by screening with prostatespecific antigen develop into clinical cancer if left undiagnosed? A comparison of two populationbased studies in Sweden. BJU Int. 2000; 85(9):1078-1084. [PubMed: 10848699]

11. Crawford ED, Abrahamsson PA. PSA-based Screening for Prostate Cancer: How Does It Compare with Other Cancer Screening Tests? Eur Urol. 2008; 54(2):262-273. [PubMed: 18556114]

12. Ilic D, O'Connor D, Green S, Wilt T. Screening for prostate cancer: a Cochrane systematic review. Cancer Causes Control. 2007; 18(3):279-285. [PubMed: 17206534]

13. Roobol MJ, Schroder FH. European Randomized study of Screening for Prostate Cancer (ERSPC): rationale, structure and preliminary results. BJU Int. 2003; 92(Suppl 2):1-122. [PubMed: 14983946]

14. Wolters T, Roobol MJ, Steyerberg EW, et al. The effect of study arm on prostate cancer treatment in the large screening trial ERSPC. Int J Cancer. 2010; 126(10):2387-2393. [PubMed: 19739124]

15. European Standard Population. Office for National Statistics. Newport, UK: at http:// www.statistics.gov.uk/StatBase/xsdataset.asp?vlnk=1260\&More $=Y$ [Accessed November 13, 2008]

16. The Cost-Effectiveness Analysis Registry, Center for the Evaluation of Value and Risk in Health. Boston: ICRHPS, Tufts Medical Center; at http://www.cearegistry.org [Accessed November 13, 2008]

17. Essink-Bot ML, de Koning HJ, Nijs HG, Kirkels WJ, van der Maas PJ, Schröder FH. Short-term effects of population-based screening for prostate cancer on health-related quality of life. J Natl Cancer Inst. 1998; 90(12):925-931. [PubMed: 9637143]

18. Sanda MG, Dunn RL, Michalski J, et al. Quality of life and satisfaction with outcome among prostate-cancer survivors. N Engl J Med. 2008; 358(12):1250-1261. [PubMed: 18354103] 
19. Stewart ST, Lenert L, Bhatnagar V, Kaplan RM. Utilities for prostate cancer health states in men aged 60 and older. Medical care. 2005; 43(4):347-355. [PubMed: 15778638]

20. Prostate cancer incidence and mortality rates. The Netherlands: Comprehensive Cancer Centers, Utrecht; at http://www.ikcnet.nl [Accessed March 18, 2009]

21. Klotz L, Zhang L, Lam A, Nam R, Mamedov A, Loblaw A. Clinical results of long-term follow-up of a large, active surveillance cohort with localized prostate cancer. J Clin Oncol. 2010; 28(1):126131. [PubMed: 19917860]

22. Albertsen PC, Hanley JA, Fine J. 20-year outcomes following conservative management of clinically localized prostate cancer. JAMA. 2005; 293(17):2095-2101. [PubMed: 15870412]

23. Bill-Axelson A, Holmberg L, Filen F, et al. Radical prostatectomy versus watchful waiting in localized prostate cancer: the Scandinavian prostate cancer group-4 randomized trial. J Natl Cancer Inst. 2008; 100(16):1144-1154. [PubMed: 18695132]

24. Roobol MJ, Kerkhof M, Schröder FH, et al. Prostate cancer mortality reduction by prostatespecific antigen-based screening adjusted for nonattendance and contamination in the European Randomised Study of Screening for Prostate Cancer (ERSPC). Eur Urol. 2009; 56(4):584-591. [PubMed: 19660851]

25. Carlsson S, Aus G, Bergdahl S, et al. The excess burden of side-effects from treatment in men allocated to screening for prostate cancer. The Goteborg randomised population-based prostate cancer screening trial. Eur J Cancer. 2011; 47(4):545-553. [PubMed: 21087857]

26. Roobol MJ, Steyerberg EW, Kranse R, et al. A Risk-Based Strategy Improves Prostate-Specific Antigen-Driven Detection of Prostate Cancer. Eur Urol. 2010; 57(1):79-85. [PubMed: 19733959]

27. Steyerberg EW, Roobol MJ, Kattan MW, van der Kwast TH, de Koning HJ, Schröder FH. Prediction of indolent prostate cancer: validation and updating of a prognostic nomogram. J Urol. 2007; 177(1):107-112. discussion 12. [PubMed: 17162015]

28. Stattin P, Holmberg E, Bratt O, et al. Surveillance and deferred treatment for localized prostate cancer. Population based study in the National Prostate Cancer Register of Sweden. J Urol. 2008; 180(6):2423-2429. discussion 9-30. [PubMed: 18930283]

29. van den Bergh RC, Roemeling S, Roobol MJ, et al. Outcomes of men with screen-detected prostate cancer eligible for active surveillance who were managed expectantly. Eur Urol. 2009; 55(1):1-8. [PubMed: 18805628]

30. de Haes JC, de Koning HJ, van Oortmarssen GJ, van Agt HM, de Bruyn AE, van Der Maas PJ. The impact of a breast cancer screening programme on quality-adjusted life-years. Int J Cancer. 1991; 49(4):538-544. [PubMed: 1917155]

31. Johansson E, Steineck G, Holmberg L, et al. Long-term quality-of-life outcomes after radical prostatectomy or watchful waiting: the Scandinavian Prostate Cancer Group-4 randomised trial. Lancet Oncol. 2011; 12(9):891-899. [PubMed: 21821474]

32. Smith DP, King MT, Egger S, et al. Quality of life three years after diagnosis of localised prostate cancer: population based cohort study. BMJ (Clinical research ed. 2009; 339:b4817.

33. Korfage IJ, Hak T, de Koning HJ, Essink-Bot ML. Patients' perceptions of the side-effects of prostate cancer treatment--a qualitative interview study. Social science \& medicine (1982). 2006; 63(4):911-919. [PubMed: 16798130]

34. Madalinska JB, Essink-Bot ML, de Koning HJ, Kirkels WJ, van der Maas PJ, Schröder FH. Health-related quality-of-life effects of radical prostatectomy and primary radiotherapy for screendetected or clinically diagnosed localized prostate cancer. J Clin Oncol. 2001; 19(6):1619-1628. [PubMed: 11250990]

35. Mols F, Korfage IJ, Vingerhoets AJ, et al. Bowel, urinary, and sexual problems among long-term prostate cancer survivors: a population-based study. Int J Radiat Oncol Biol Phys. 2009; 73(1):30 38. [PubMed: 18538503]

36. Thong MS, Mols F, Kil PJ, Korfage IJ, van de Poll-Franse LV. Prostate cancer survivors who would be eligible for active surveillance but were either treated with radiotherapy or managed expectantly: comparisons on long-term quality of life and symptom burden. BJU Int. 2010; 105(5): 652-658. [PubMed: 19747357] 
37. Potosky AL, Davis WW, Hoffman RM, et al. Five-year outcomes after prostatectomy or radiotherapy for prostate cancer: the prostate cancer outcomes study. J Natl Cancer Inst. 2004; 96(18):1358-1367. [PubMed: 15367568]

38. Hayes JH, Ollendorf DA, Pearson SD, et al. Active surveillance compared with initial treatment for men with low-risk prostate cancer: a decision analysis. JAMA. 2010; 304(21):2373-2380. [PubMed: 21119084]

39. Chen RC, Clark JA, Talcott JA. Individualizing quality-of-life outcomes reporting: how localized prostate cancer treatments affect patients with different levels of baseline urinary, bowel, and sexual function. J Clin Oncol. 2009; 27(24):3916-3922. [PubMed: 19620493]

40. Auvinen A, Raitanen J, Moss S, et al. Test sensitivity in the European prostate cancer screening trial: results from Finland, Sweden, and the Netherlands. Cancer Epidemiol Biomarkers Prev. 2009; 18(7):2000-2005. [PubMed: 19567505]

41. Boorjian SA, Karnes RJ, Viterbo R, et al. Long-term survival after radical prostatectomy versus external-beam radiotherapy for patients with high-risk prostate cancer. Cancer. 2011; 117(13): 2883-2891. [PubMed: 21692049]

42. Cooperberg MR, Vickers AJ, Broering JM, Carroll PR. Comparative risk-adjusted mortality outcomes after primary surgery, radiotherapy, or androgen-deprivation therapy for localized prostate cancer. Cancer. 2010; 116(22):5226-5234. [PubMed: 20690197]

43. Korfage IJ, de Koning HJ, Roobol M, Schröder FH, Essink-Bot ML. Prostate cancer diagnosis: the impact on patients' mental health. Eur J Cancer. 2006; 42(2):165-170. [PubMed: 16326098]

44. Bennett CL, Matchar D, McCrory D, McLeod DG, Crawford ED, Hillner BE. Cost-effective models for flutamide for prostate carcinoma patients: are they helpful to policy makers? Cancer. 1996; 77(9):1854-1861. [PubMed: 8646685]

45. Zeliadt SB, Etzioni RD, Penson DF, Thompson IM, Ramsey SD. Lifetime implications and costeffectiveness of using finasteride to prevent prostate cancer. American J Med. 2005; 118(8):850 857.

46. Cooperberg MR, Carroll PR, Klotz L. Active surveillance for prostate cancer: progress and promise. J Clin Oncol. 2011; 29(27):3669-3676. [PubMed: 21825257]

47. van den Bergh RC, Roemeling S, Roobol MJ, Roobol W, Schröder FH, Bangma CH. Prospective validation of active surveillance in prostate cancer: the PRIAS study. Eur Urol. 2007; 52(6):1560 1563. [PubMed: 17532115]

48. Konski A, Sherman E, Krahn M, et al. Economic analysis of a phase III clinical trial evaluating the addition of total androgen suppression to radiation versus radiation alone for locally advanced prostate cancer (Radiation Therapy Oncology Group protocol 86-10). Int J Radiat Oncol Biol Phys. 2005; 63(3):788-794. [PubMed: 16109464]

49. Calvert NW, Morgan AB, Catto JW, et al. Effectiveness and cost-effectiveness of prognostic markers in prostate cancer. Br J Cancer. 2003; 88(1):31-35. [PubMed: 12556955]

50. Konski A, Watkins-Bruner D, Brereton H, Feigenberg S, Hanks G. Long-term hormone therapy and radiation is cost-effective for patients with locally advanced prostate carcinoma. Cancer. 2006; 106(1):51-57. [PubMed: 16323171]

51. Moeremans K, Caekelbergh K, Annemans L. Cost-effectiveness analysis of bicalutamide (Casodex) for adjuvant treatment of early prostate cancer. Value Health. 2004; 7(4):472-481. [PubMed: 15449639]

52. Penson DF, Ramsey S, Veenstra D, Clarke L, Gandhi S, Hirsch M. The cost-effectiveness of combined androgen blockade with bicalutamide and luteinizing hormone releasing hormone agonist in men with metastatic prostate cancer. J Urol. 2005; 174(2):547-552. discussion 52. [PubMed: 16006889]

53. Ramsey S, Veenstra D, Clarke L, Gandhi S, Hirsch M, Penson D. Is combined androgen blockade with bicalutamide cost-effective compared with combined androgen blockade with flutamide? Urology. 2005; 66(4):835-839. [PubMed: 16230148]

54. Damber JE, Aus G. Prostate cancer. Lancet. 2008; 371(9625):1710-1721. [PubMed: 18486743] 


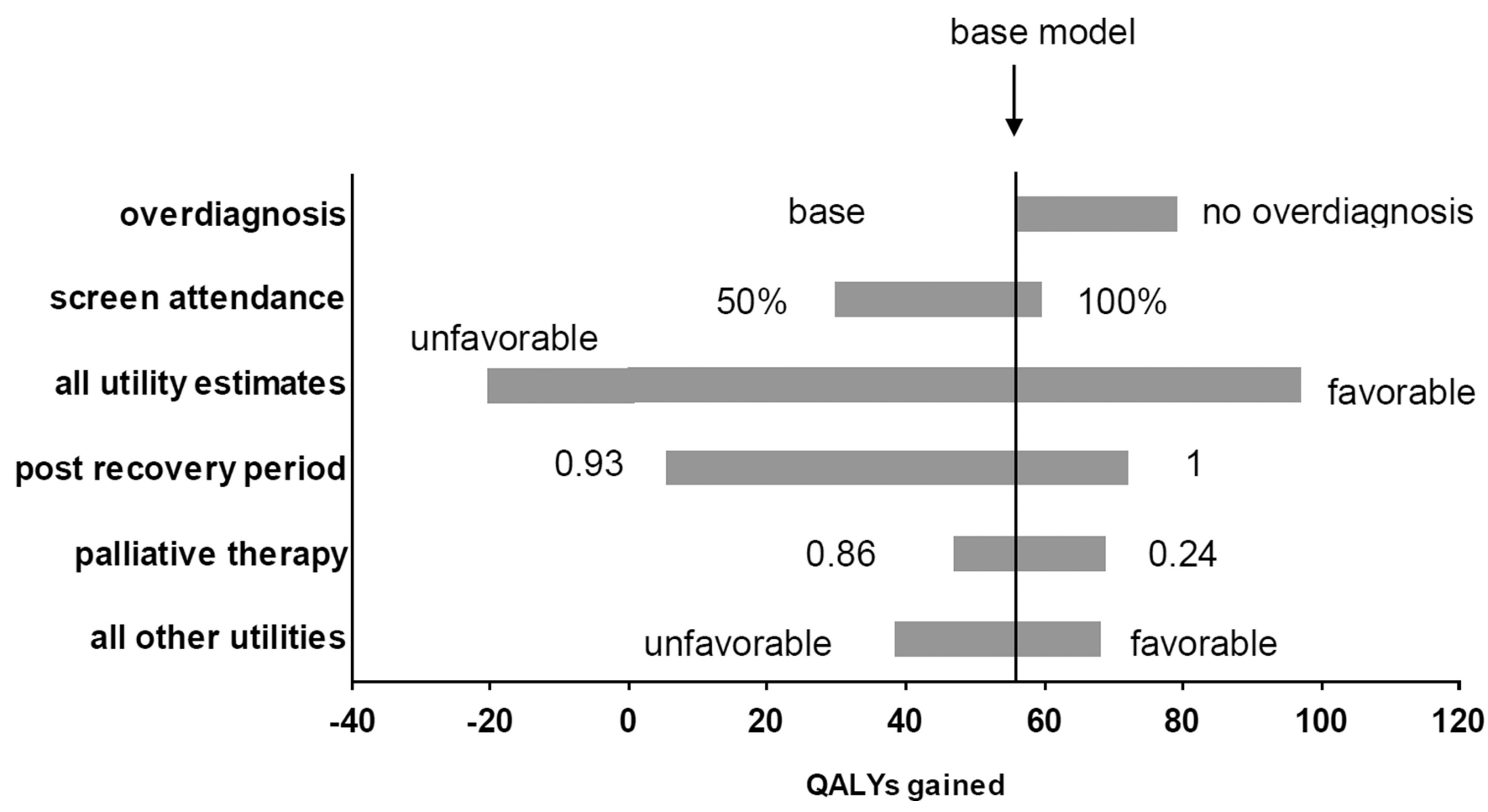

Figure 1. Effect of various modeling assumptions on QALYs gained in comparison with the base model (56 QALYs gained)

The assumptions are: 1) no overdiagnosis, 2) screen attendance of 50\% and 100\%, 3) all unfavorable and favorable utility estimates, 4) utility estimate of 0.93 and 1 for the life-time post-recovery period, 5) utility estimate of 0.86 and 0.24 for palliative therapy, and 6) the utility estimates for the post-recovery period (0.95) and palliative therapy (0.6) as used in the base model combined with the unfavorable and favorable utility estimates of all other health states. 


\section{롤 \\ 文}

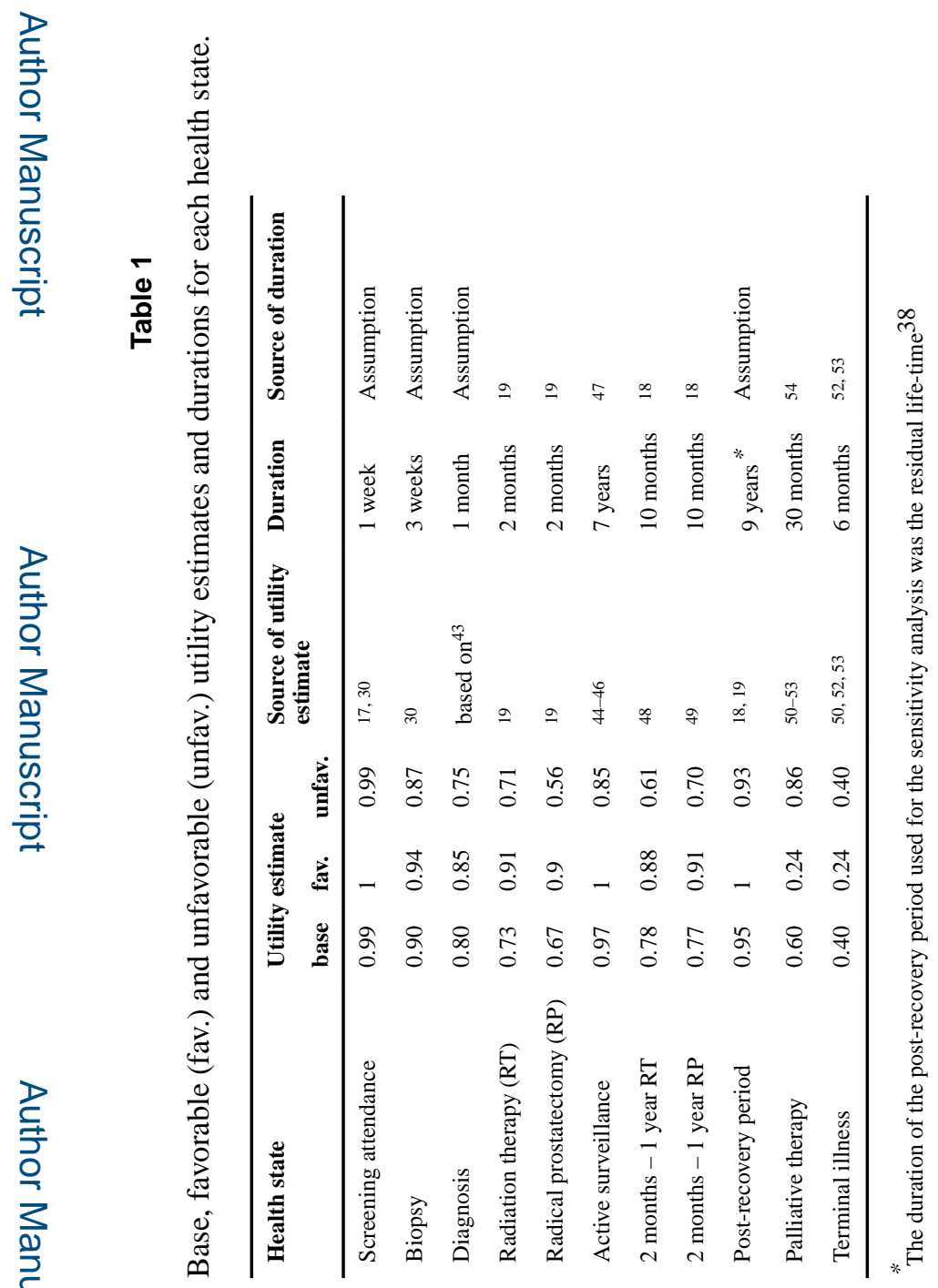




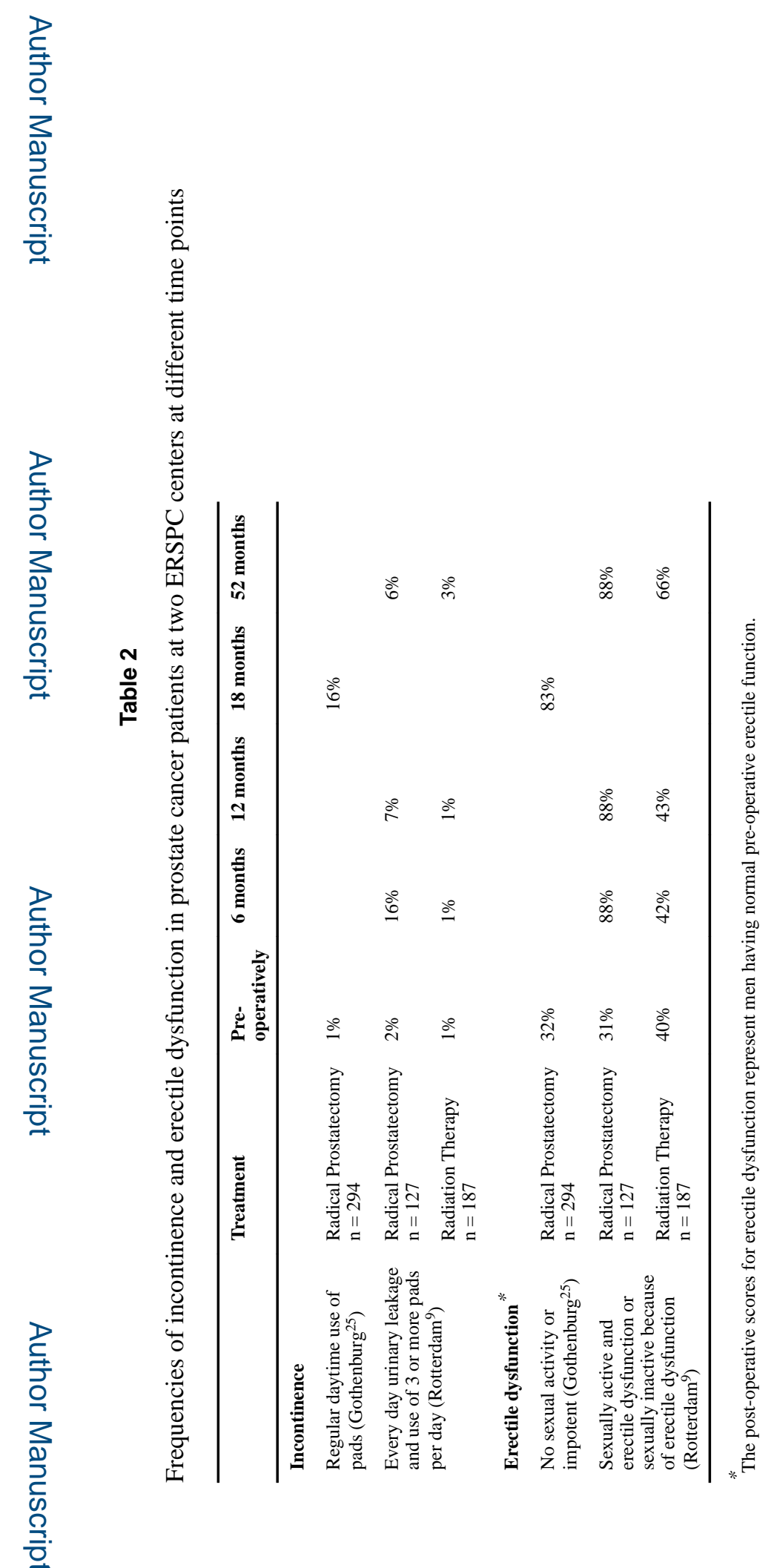

N Engl J Med. Author manuscript; available in PMC 2016 August 12. 
Heijnsdijk et al.

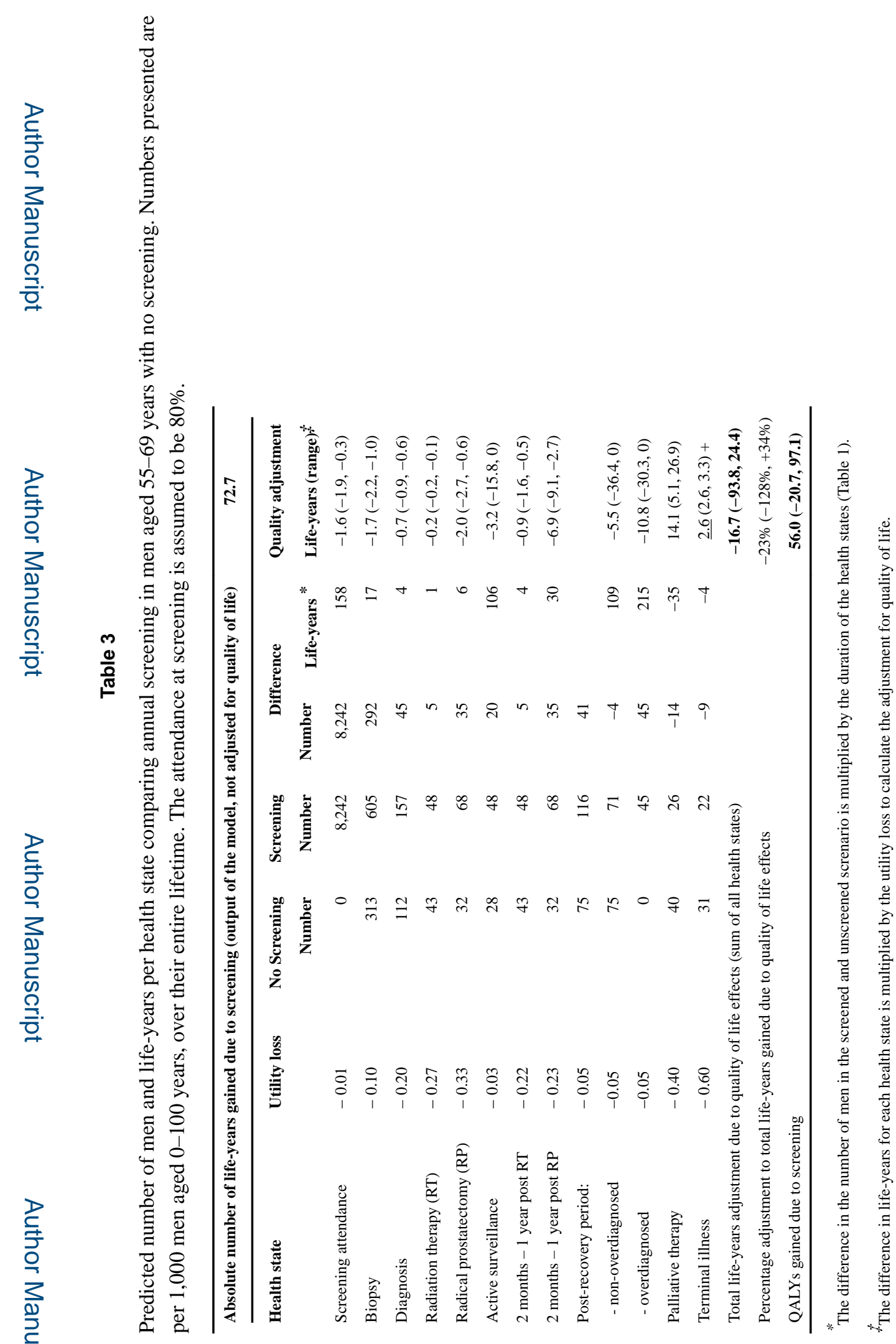

NEngl J Med. Author manuscript; available in PMC 2016 August 12. 
Heijnsdijk et al.

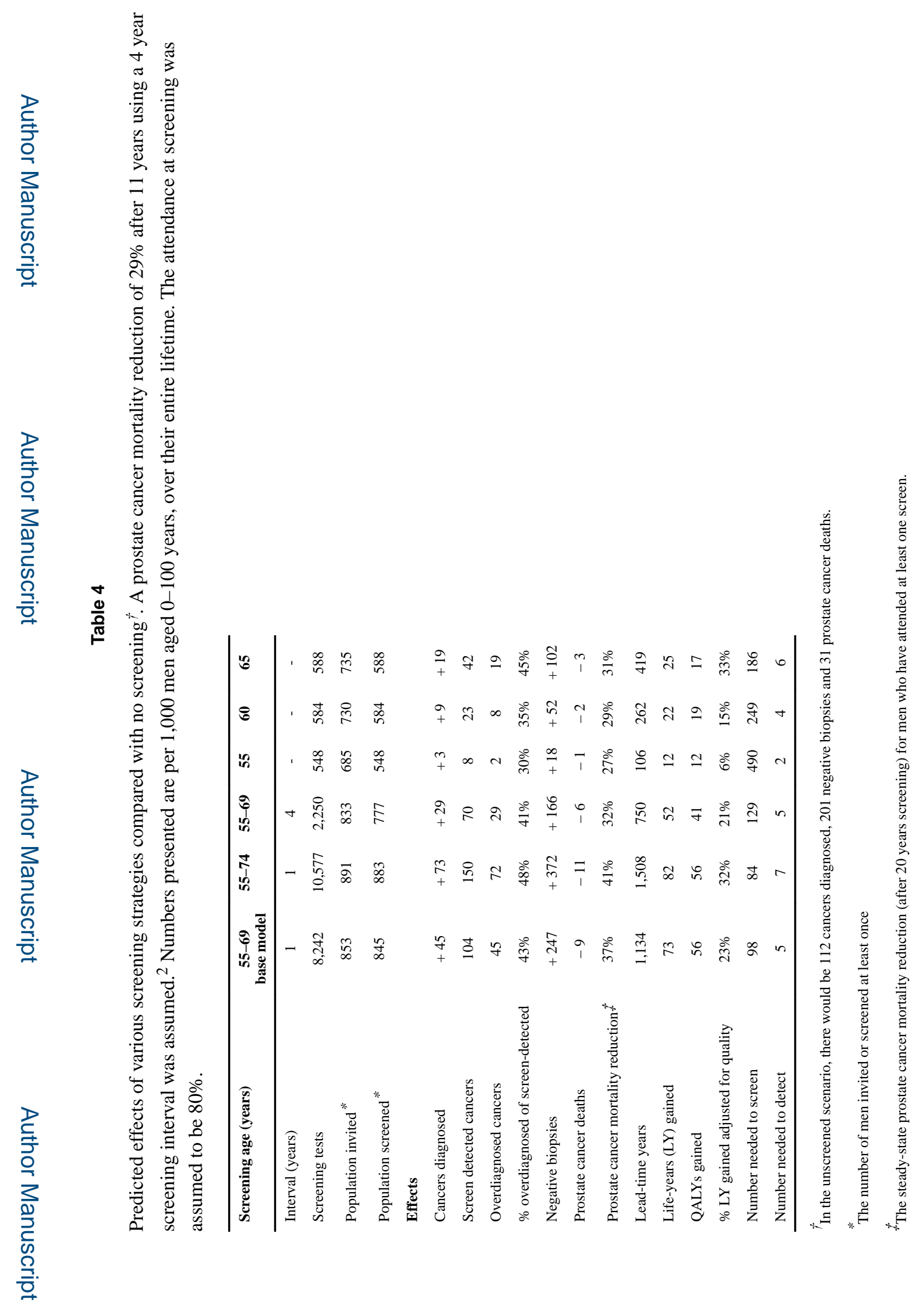

NEngl J Med. Author manuscript; available in PMC 2016 August 12. 